\title{
Effect of Welding Current and Voltage on the Mechanical Properties of Wrought (6063) Aluminium Alloy
}

\author{
Oladele Isiaka Oluwole*, Omotoyinbo Joseph Ajibade \\ Metallurgical and Materials Engineering Department, \\ Federal University of Technology, Akure, Ondo State, Nigeria
}

Received: May 20, 2009; Revised: February 23, 2010

\begin{abstract}
This work was carried out to investigate the effect of welded joints on the mechanical properties of wrought (6063) aluminium alloy. The study revealed the influence of current and voltage on the welded joint as well as the mechanical properties of the alloy. The alloy samples were welded together by metal inert gas welding process at varying values of current and voltage after which mechanical tests were performed on the welded samples. The microstructural examination of the various fusion zones obtained was carried out. Appreciable variations in the properties of the welded samples were observed due to changes in the microstructural features of the alloys. It was concluded that variation of current and voltage remarkably affect the mechanical properties of the wrought 6063 Aluminium alloy. As the voltage increases from 25 to $30 \mathrm{~V}$, the ultimate tensile strengths and hardness values increases while the impact strengths decreases but the current did not show such trend.
\end{abstract}

Keywords: welding current, welding voltage, welded joints, wrought 6063-aluminium alloy, mechanical properties

\section{Introduction}

Aluminium and its alloys are part of the major engineering materials that are indispensable for now. The reasons for this are many but some of them are due its light weight and corrosion resistance among other properties. As a result of its wide areas of applications, aluminium and its alloy keep on attracting different areas of research. The need to improve its properties as well as prevent failure of the materials most especially during service is of great priority.

Aluminum alloys are more frequently welded than any other types of nonferrous alloys because of their widespread applications and fairly good weldability. In general, higher strength aluminum alloys are more susceptible to (i) hot cracking in the fusion zone and the Partially Melted Zone (PMZ) and (ii) losses of strength/ductility in the Heat Affected Zone ( HAZ) ${ }^{8}$. Wrought aluminium alloy is the term used for the alloy that is suitable for shaping by a working process such as forging, rolling and extrusion. Al-Mg-Si alloy is a typical example of wrought aluminium alloy widely used for structural applications with medium strength ${ }^{1,3,4}$.

The alloy of aluminium and copper are difficult to weld because of the high thermal conductivity, high thermal expansion and a tendency to give porous welds ${ }^{8}$. The high thermal conductivity means that there is a high rate of cooling and so there is difficulty in heating up the parent metal round the weld zone to a high enough temperature to give complete fusion with the weld pool. The high coefficient of expansion means that significant residual stresses are produced as a result of the weld area expansion being constrained by the colder surrounding parent metal. Porosity arises because the metal in the molten state absorbs hydrogen from the sources as the welding flame, fluxes and atmospheric moisture and when the weld cools, this hydrogen is released ${ }^{3}$.

The weldability of aluminium alloys varies significantly depending on the chemical composition of the alloy used. Aluminium alloys are susceptible to hot cracking, and to combat the problem, welders increase the welding speed to lower the heat input (Wikipedia).
Aluminium alloys are readily available in various product forms. To establish a proper welding procedure, it is necessary to know the material properties of the aluminium alloy being welded. The $6 \mathrm{xxx}$ series alloys contain silicon and magnesium approximately in the proportions required for formation of magnesium silicide $\left(\mathrm{Mg}_{2} \mathrm{Si}\right)$, thus making them heat treatable. It has good formability, weldability, machinability and relatively good corrosion resistance, with medium strength ${ }^{6,7}$

Metal inert gas welding is the most economic process for metal thicker than $6 \mathrm{~mm}$ diameter. Control of penetration is difficult for thin gauge material. In the metal inert gas process a direct current (D.C.) arc of reverse polarity is struck between the work piece and a continuously fed aluminium wire which acts as both the filler and the electrode. Fluxes are unnecessary. The arc itself cleans the electrode and welds pool, whilst re-oxidation is prevented by a shield of inert gas which envelopes the area. Since the electrode is continuous, welding speeds are high with small arc size. Owing to the higher average rate at which welds can be completed, it is well suitable for the welding of aluminium ${ }^{5,6}$.

In arc welding, the length of the arc is directly related to the voltage, and the amount of heat input is related to the current ${ }^{2}$. It was for this purpose that the research work was focused on the variation effect of welding current and welding voltage on the mechanical properties of wrought (6063) aluminium alloy. The results from the research are to guide on the possibility of welding fractured wrought (6063) aluminium alloy in service and during fabrication.

\section{Experimental Procedure}

\subsection{Parent material}

The parent material used in this study was wrought (6063) alloy. The Composition analysis as revealed by ARL3460 metals Argon analyzer was as shown in Table 1. 
Table 1. Chemical composition of the wrought (6063) aluminium alloy (in wt. (\%)).

\begin{tabular}{cccccccccccc}
\hline $\mathrm{Al}$ & $\mathrm{Mg}$ & $\mathrm{SI}$ & $\mathrm{Fe}$ & $\mathrm{Cu}$ & $\mathrm{Mn}$ & $\mathrm{Zn}$ & $\mathrm{Cr}$ & $\mathrm{Ti}$ & $\mathrm{Ca}$ & $\mathrm{Sr}$ \\
\hline 98.7745 & 0.5504 & 0.4076 & 0.1970 & 0.1667 & 0.0142 & 0.0115 & 0.0144 & 0.0132 & 0.0006 & 0.0001 \\
\hline
\end{tabular}

\subsection{Welding procedure}

Ten samples each of tensile, impact and hardness were prepared while five samples were prepared for microstructural examination. The samples for tensile, impact and hardness were divided into five sets of which four sets were cut into two parts and welded together at the chosen welding current and voltage. The material was machined on the lathe machine into tensile and impact samples while hand hack saw was used to prepare the hardness test and microstructural examination samples.

The samples for tensile, impact and hardness tests were divided into five sets (two samples for each variable) for the various welding conditions. All the samples except the control sample for each of the tests were cut into two and welded together by metal inert gas welding process. The welding equipment used for the research work was MACRO HF MIG, $50 \mathrm{HZ}$ and electrode. Before welding, the edges of the test piece to be joined were prepared by filling and cleaning of the surface to obtain a good weld. The selected Conditions for the welding operations are as follows:

At constant voltage; the welding current was varied as $I_{1}=75 \mathrm{~A}$ and $\mathrm{I}_{2}=100 \mathrm{~A}$.

At constant current; the welding voltage was varied as: $\mathrm{V}_{1}=25 \mathrm{~V}$ and $\mathrm{V}_{2}=30 \mathrm{~V}$.

In order to obtain a stable arc, good protective atmosphere, and reduce spatter, welding was first carried out on a rough sample before transferring it to the work piece.

\section{Mechanical Tests}

\subsection{Tensile test}

The welded samples were tested for tensile strength using the Monsanto tensile machine. The edges of the test samples were fitted into the jaws of the testing machine and subjected to tensile stresses until the sample fractured. During the test, the various stress-strain diagrams were drawn for each of the sample from where the tensile load is determined. This is used in determining the strength and stiffness of the materials.

\subsection{Impact test}

The impact test was carried out using the Charpy impact machine. The test piece is supported at each end while notched at the mid-point between the two supports. The notch is on the face directly opposite to where the pendulum strikes the test piece. The V-notch was $2 \mathrm{~mm}$ deep and of angle $45^{\circ}$. The energy absorbed in breaking the test piece is measured in joules. The ability of the material to withstand the applied load is referred to as toughness.

\subsection{Hardness test}

Hardness test was carried out using Brinell hardness testing machine. The surface was first polished and diamond indentor was used to make dent on the polished surface and the diameter of the dent measured.

\subsection{Metallographic examination}

The microstructural details of the welded and the control samples were studied. The welded samples were carefully sectioned at the fusion zone and grinding was then carried out on emery papers of progressively finer grade (40, 60, 400 and 600). The final polishing was carried out carefully to produce mirror like and ridges free surface. The samples were etched with $0.1 \mathrm{M}$ concentration of hydroxide solution $(\mathrm{OH})_{4}$ with $(\times 100)$ magnification.

\section{Results and Discussion}

\subsection{The effect of variation of the welding parameters on the tensile properties of the samples.}

Figure 1 shows the Ultimate Tensile Strength results. It was revealed that samples that serves as the control has the best ultimate tensile strength of $150.42 \mathrm{~N} . \mathrm{mm}^{-2}$ followed by samples welded at current, $I_{2}=100 \mathrm{~A}$ with ultimate tensile strength of $131.15 \mathrm{~N} . \mathrm{mm}^{-2}$ which are more than the values obtained for current, $\mathrm{I}_{1}=75 \mathrm{~A}$ and voltage, $\mathrm{V}_{2}=30 \mathrm{~V}$ with ultimate tensile strengths of 96.77 and $93.72 \mathrm{~N} . \mathrm{mm}^{-2}$ respectively.

\subsection{The effect of variation of the welding parameters on the impact energy of the samples.}

From the result in Figure 2, it was observed that the impact strength of the control sample was the best with an average value of $26.04 \mathrm{~J}$ while the welded samples have low impact strength with respect to the control. All the values fall within a close range the highest being that of $\mathrm{V}_{1}=25 \mathrm{~V}$ with an impact strength of $11.19 \mathrm{~J}$. This is a measure of the toughness of the materials.

\subsection{The effect of variation of the welding parameters on the hardness of the samples.}

Figure 3 shows the hardness result. Samples welded at current, $I_{1}=75 \mathrm{~A}, V_{2}=30 \mathrm{~V}$ as well as current, $I_{2}=100 \mathrm{~A}$ and have high hardness values of $35.40,33.90$ and $31.05 \mathrm{HBN}$ respectively more than the control sample which has $28.10 \mathrm{HBN}$. The hardness value is a measure of the resistance of a material to indentation.

\subsection{The effect of variation of the welding parameters on the microstructure of the samples.}

The micrographs show the melting reaction of secondary $\mathrm{Mg}_{2} \mathrm{Si}$ particles together with their surrounding $\mathrm{Al}$ matrix ${ }^{7}$. The general behaviour of the different samples depend on the effect of precipitation that takes place at the micro structural level as shown in the fgures below.

In Figure 4, the micrograph of welded sample subjected to current $\mathrm{I}_{1}=75 \mathrm{~A}$ processing show fine grains of well diffused $\mathrm{Mg}_{2} \mathrm{Si}$ compound in the $\mathrm{Al}$ matrix. These fine particles are responsible for the high and improved ultimate tensile strength and hardness values obtained in Figures 1 and 3 above.

From Figure 5, the micrographs of welded sample subjected to current $\mathrm{I}_{2}=100 \mathrm{~A}$ processing show well diffused equiaxed compound of $\mathrm{Mg}_{2} \mathrm{Si}$ in $\mathrm{Al}$ matrix. This structure also enhanced good mechanical properties for the sample in terms of the ultimate tensile strength and hardness values. These were shown in Figures 1 and 3 above.

The micrograph of welded sample subjected to voltage $\mathrm{V}_{1}=25 \mathrm{~V}$ processing in Figure 6 show high concentration of the $\mathrm{Mg}_{2} \mathrm{Si}$ compound at different parts of the sample. There is no uniform 


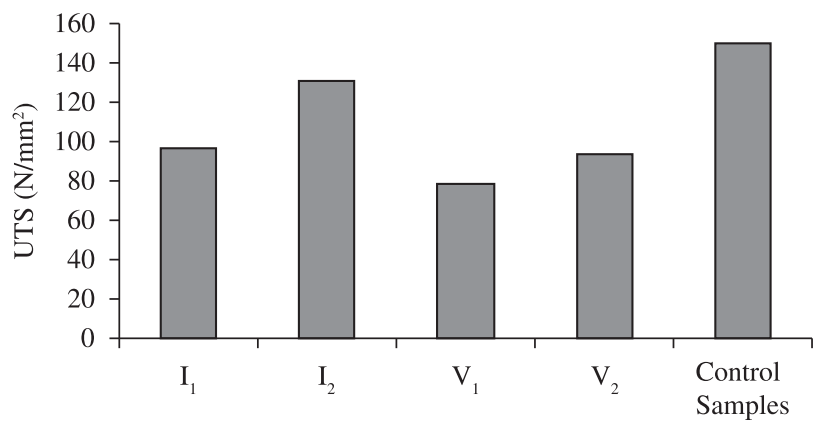

Figure 1. Average value of the ultimate tensile strength (UTS) of the samples at the various welding conditions in N.mm .

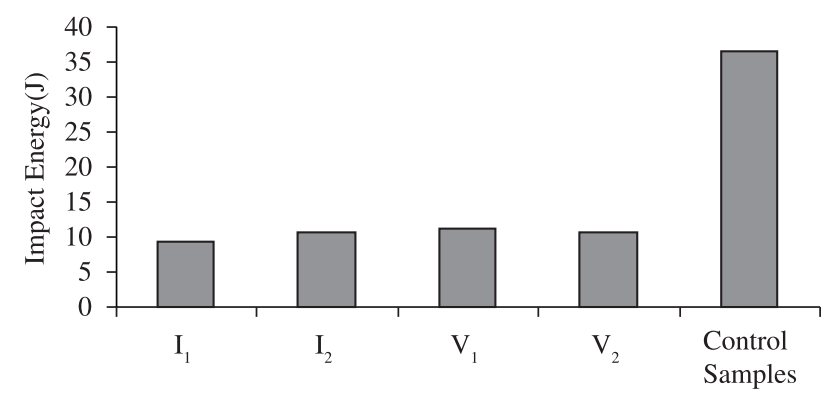

Figure 2. Average values of the impact energy of the samples at the various welding conditions in $\mathrm{J}$.

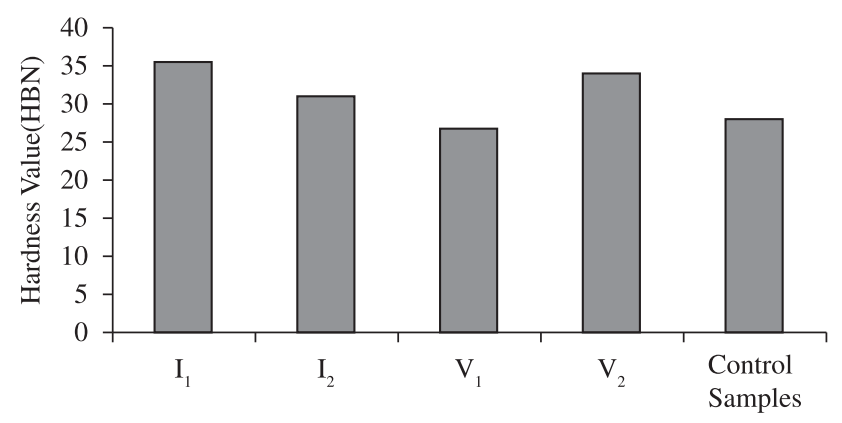

Figure 3. Average hardness values of the samples at the various welding congitions in HBN.

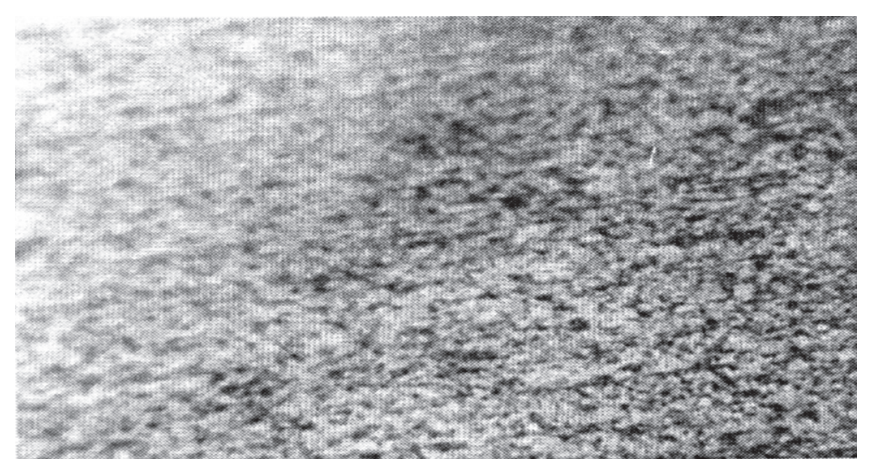

Figure 4. Micrograph of welded sample subjected to current $I_{1}=75 \mathrm{~A}$ processing $(\times 100)$.

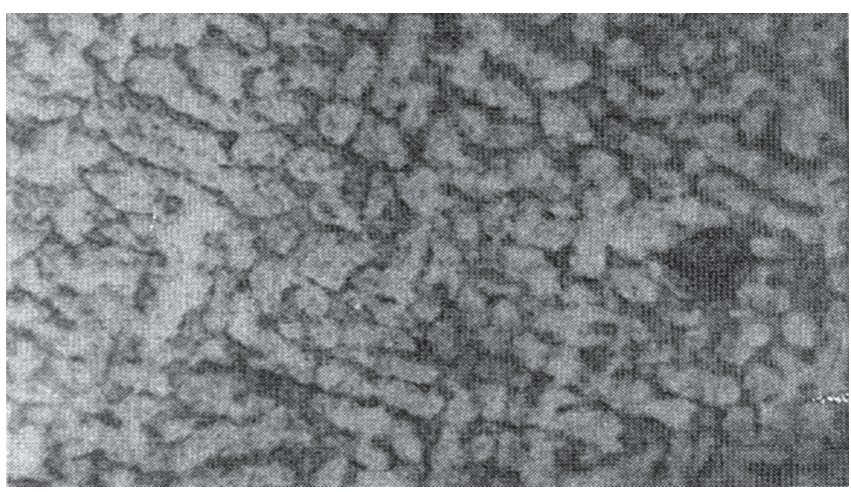

Figure 5. Micrograph of welded sample subjected to current $I_{2}=100 \mathrm{~A}$ processing $(\times 100)$.

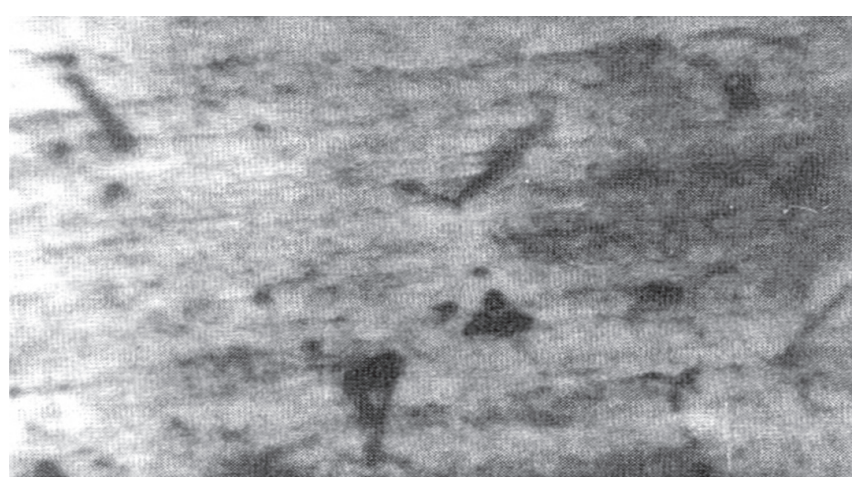

Figure 6. Micrograph of welded sample subjected to voltage $\mathrm{V}_{1}=25 \mathrm{~V}$ processing $(\times 100)$.

diffusion of the precipitated compound and hence, the obtained ultimate tensile strength and hardness values are less than that of $\mathrm{I}_{1}$ and $\mathrm{I}_{2}$. Figures 1 and 3 above show the values. However, it has the best impact strength with respect to other welded samples.

Figure 7 revealed the micrograph of the sample welded at voltage $\mathrm{V}_{2}=30 \mathrm{~V}$ revealed the deposition of the precipitate of $\mathrm{Mg}_{2} \mathrm{Si}$ in $\mathrm{Al}$ matrix at the grain boundaries with a cluster at a point close to the edge. This enhanced good ultimate tensile strength and hardness properties as obtained in Figures 1 and 3.

Figure 8 is the micrograph of the control sample. It shows fine grains of well diffused $\mathrm{Mg}_{2} \mathrm{Si}$ compound in the $\mathrm{Al}$ matrix. It possess the best ultimate tensile strength and impact strength with good hardness values as obtained in Figures 1 and 3 above. These fine particles are responsible for the good mechanical properties obtained.

At these welding conditions, it was observed that the wrought (6063) aluminium alloy that serves as the control have the best ultimate tensile strength of $150.42 \mathrm{~N} . \mathrm{mm}^{-2}$ and impact strength of $36.48 \mathrm{~J}$. The hardness value competes favourably with the hardness values from the welded samples as shown in Figure 3 above. Samples that were welded at constant voltage and at current, $100 \mathrm{~A}$ was observed to have the best performance close to the control sample with ultimate tensile strength of $131.15 \mathrm{~N} . \mathrm{mm}^{-2}$, hardness value of $31.05 \mathrm{HBN}$ and impact strength of $10.58 \mathrm{~J}$. These were followed by those samples that were welded at constant voltage and at current; 75 A.These has the best hardness value of $35.40 \mathrm{HBN}$ and comparable ultimate tensile strength of $96.77 \mathrm{~N} . \mathrm{mm}^{-2}$ and impact 


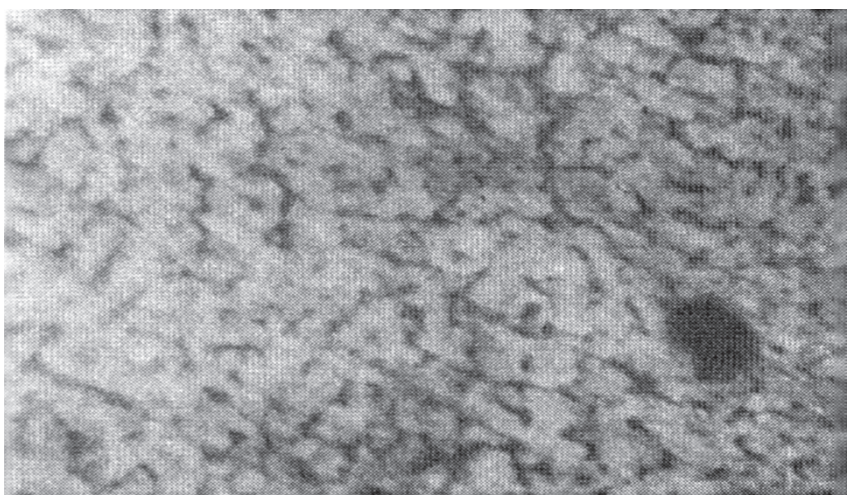

Figure 7. Micrograph of welded sample subjected to voltage $V_{2}=30 \mathrm{~V}$ processing $(\times 100)$.

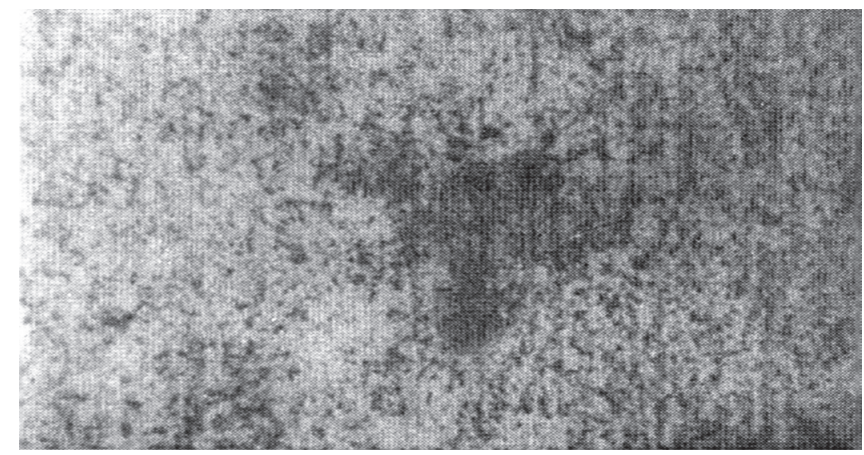

Figure 8. Micrograph of the control sample $(\times 100)$.

strength of 9.36 J. Samples that were welded at constant current and $30 \mathrm{~V}$ possess good hardness value of $33.90 \mathrm{HBN}$ and comparable ultimate tensile strength of $93.72 \mathrm{~N} . \mathrm{mm}^{-2}$ and impact strength of $10.64 \mathrm{~J}$. However, the samples that was welded at constant current and at a voltage of $25 \mathrm{~V}$ possesses the least values of ultimate tensile strength and hardness value results in comparison with the other samples except for the impact strength which is $11.19 \mathrm{~J}$. The ultimate tensile strength is $78.53 \mathrm{~N} . \mathrm{mm}^{-2}$ while the hardness value is $26.69 \mathrm{HBN}$.

\section{Conclusion}

The results of the welding of wrought (6063) aluminium alloy with the above given chemical composition and welding conditions revealed that the control sample has the best overall mechanical properties with respect to the other welded samples. However, the results revealed what are obtainable at the given welding conditions which are as follows;

i) Sample welded at constant voltage and at current $I_{2}=100 \mathrm{~A}$ have the best UTS next to the control sample while sample welded at constant voltage and at current $\mathrm{I}_{1}=75 \mathrm{~A}$ have the best hardness properties even more than that of the control sample.

ii) Welding at constant voltage and at current $\mathrm{I}_{2}=100 \mathrm{~A}$, followed by welding at constant voltage and at current $\mathrm{I}_{1}=75 \mathrm{~A}$ gave the best mechanical properties in terms of ultimate tensile strength and hardness value close to the control.

iii) The impact strengths of the welded samples at the various welding conditions are low compared to that of the control sample as a result of the changes in the microstructural features of the alloy.

iv) As the voltage increases from 25 to $30 \mathrm{~V}$, the ultimate tensile strengths and hardness values increases while the impact strengths decreases.

\section{References}

1. Anderson Jr. JD. The Airplane: a history of its technology. Reston: American Institute of Aeronautical and Astronautics; 2002.

2. International Develops International Standards For Materials - ASTM. Trends Welding Research in the United States. Ohio: Materials Park; 2003.

3. Bolton W. Engineering materials technology. 3 ed. Great Britain: Butterworth-Heinemann; 1999.

4. Flinn RA. and Trojan PK. Engineering materials and their applications. 4 ed. Orlando: Houghton Mifflin Publishers; 1990.

5. Khann OP. A Textbook of welding technology. New Delhi: Dhapat Rai; 1990.

6. Lancaster JF. Metallurgy of welding. 5 ed. London: Chapman and Hall Publisher; 1994

7. Robert BR. Metallic material specification handbook. 4 ed. Dordrecht Netherlands: Chapman and Hall; 1994.

8. Sindo K. Welding metallurgy. 2 ed. New York: John Wiley \& Sons; 2003. 